\title{
Quartz Overgrowths in Shales and Sandstones studied by EPMA and SIMS
}

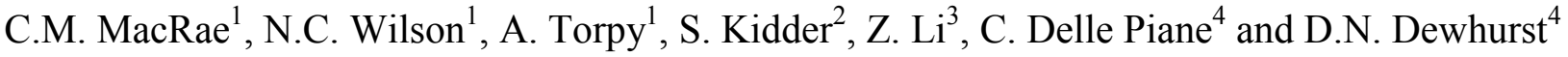 \\ ${ }^{1}$ Microbeam Laboratory, CSIRO Process Science and Engineering, Clayton South, VIC, 3169 \\ ${ }^{2}$ Earth and Atmospheric Science, City College New York, New York, USA 90031 \\ ${ }^{3}$ CSIRO Earth Science and Resource Engineering, North Ryde, NSW 2113 \\ ${ }^{4}$ CSIRO Earth Science and Resource Engineering, Kensington, WA, 6151 \\ Corresponding author: colin.macrae@csiro.au
}

Cathodoluminescence (CL) offers the ability to measure trace ionic species with relatively short acquisition times enabling large areas to be mapped with detection limits orders of magnitude below elemental detections levels acquired using x-rays under the same conditions. We have applied this technique to the investigation of quartz grains and overgrowths from shale and sandstone samples across Australia with the aim of better constraining the formation conditions of these types of cement. Recent experimental calibration of $\mathrm{Ti}$ concentration in quartz [1] provides the basis for a quantitative examination of crystal growth in both hydrothermal and detrital forms. Quartz contains trace element fluctuations at the sub-micron to micron length scale, which are records of the complex interaction between crystals and their host magmas or pore fluids. By combining spectral CL mapping [2, 3], deconvolution and elemental analysis to provide a calibration curve, it is possible to covert a CL intensity map into a trace speciation map for $\mathrm{Ti}$ for detrital quartz. Information on the quartz overgrowths will better explain the formation conditions giving rise to them.

Cathodoluminescence and x-ray spectral maps were collected on a range of quartz-bearing sandstones and shales. Figure 1 shows a sample from the Goldwyer formation in the Canning Basin (Western Australia). Maps were acquired using a JEOL 8500F equipped with WDS, spectral EDS and an integrated grating spectrometer $(200-980 \mathrm{~nm})$ with a high sensitivity CCD. Conditions were chosen so that the CL emission spectra behaved with a linear response to beam current and no beam damage was observable on the mapped grains, indicating that we are below the damage threshold for quartz. The CL images show quartz grains with mid-blue to bright intensity luminescence representing quartz which has been transported to this region and a dark-blue/lower intensity luminescence intergrowths bonding quartz grains together 5-30 $\mu$ in wide (Fig. 1). The CL maps have been fitted using five Gaussians [1.95eV Non Bridging Oxygen Hole, 2.41eV Self trapped exciton (STE), $2.79 \mathrm{eV}\left(\mathrm{Ti}^{4+}\right)$, hydro peak $(2.90 \mathrm{eV})$ and $3.66 \mathrm{eV}$ non-linear response] using a least squares fitting approach. To calibrate the CL emission peak at $2.79 \mathrm{eV}$ against $\mathrm{Ti}$, a number of quantitative point analyses were performed using the electron microprobe and the resulting calibration curve is shown in Figure 2. In addition calibration was also performed using a CAMECA $7 \mathrm{f} \mathrm{SIMS.} \mathrm{The} \mathrm{quartz} \mathrm{overgrowths} \mathrm{show} \mathrm{no} \mathrm{measurable} \mathrm{variation} \mathrm{with} \mathrm{CL} \mathrm{intensity} \mathrm{and} \mathrm{this} \mathrm{probably}$ indicates it has formed quickly, at low temperature, and the $2.79 \mathrm{eV}$ centre has not been incorporated. A correlation between the $2.90 \mathrm{eV}$ peak and quartz overgrowths has been observed.

\section{References:}

1. H D.A. Wark and E.B. Watson. Contrib. Mineral. Petrol. 152 (2006) 743.

2. W.P. Leeman et al., Microsc. Microanal. 18, 1322-1341, (2012).

3. C.M. MacRae et al., Microsc. Microanal. 16, Suppl. 2, (2010). 808 

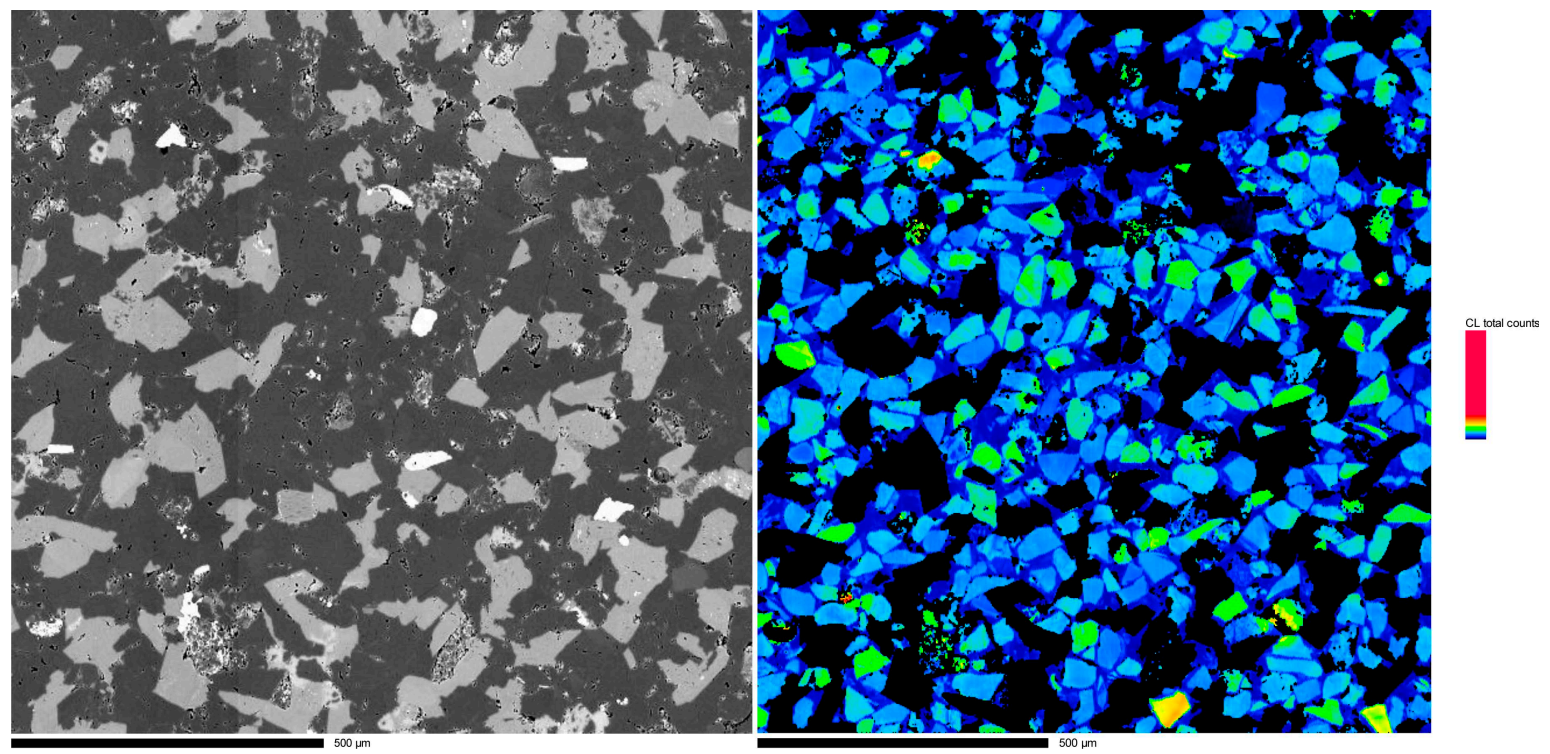

Figure 1. (left) Backscattered electron map of a shale from the Goldwyer Formation showing quartz (mid-grey) with little grain alignment evident; (right) A cathodoluminescence map from the same area shows detrital grains of quartz (light blue/green) overgrown by quartz cement (dark blue) which has weak cathodoluminescence. Only quartz grains are displayed in the cathodoluminescence map.

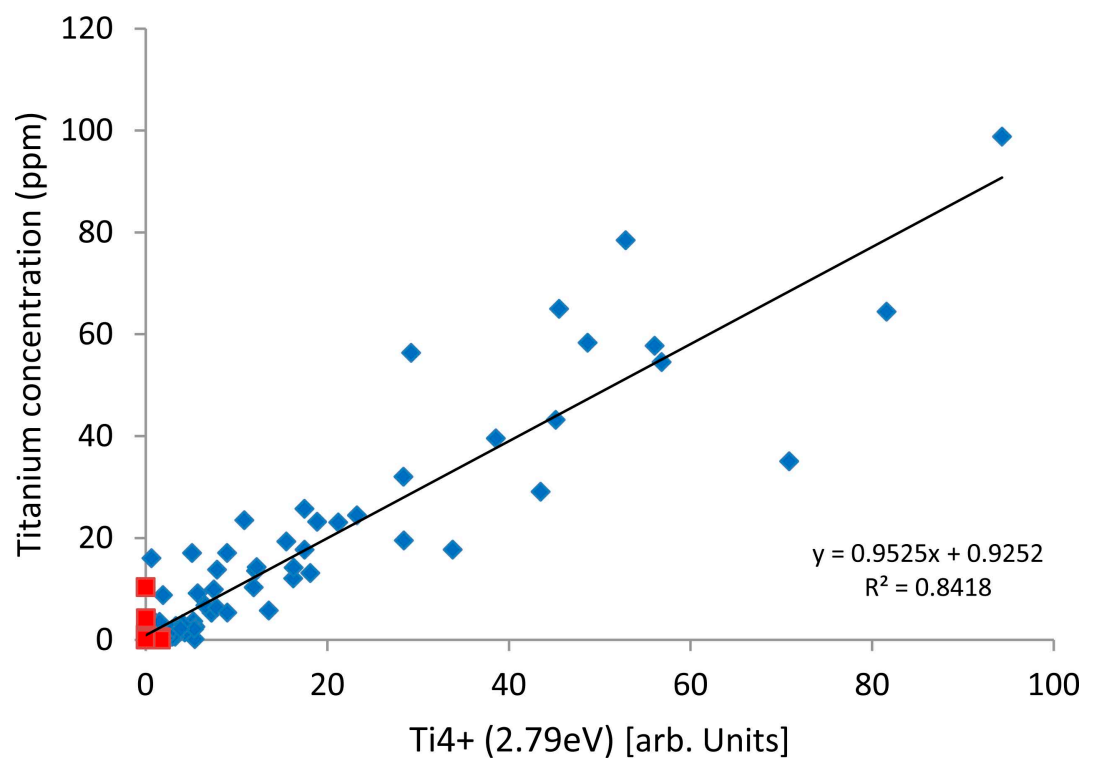

Figure 2. Scatter plot of titanium concentration measured using SIMS versus a $2.79 \mathrm{eV}$ peak associated with $\mathrm{Ti}^{4}+$. The blue points are detrital quartz grains from the sandstone while the red points are the quartz overgrowths. The detrital quartz grains exhibit the traditional association with the $2.79 \mathrm{eV}$ peak while the quartz overgrowths shows no correlation with and very low concentrations of titanium. 